\title{
Association of Disease Subtype and Duration with Echocardiographic Evidence of Pulmonary Hypertension in Myeloproliferative Neoplasm
}

\author{
Yalin Tolga Yaylalia Samet Yilmaz ${ }^{a} \quad$ Gulsum Akgun-Cagliyan ${ }^{b}$ Oguz Kilic ${ }^{a}$ \\ Emrah Kayac Hande Senol $^{d}$ Furkan Ozen $^{a}$ \\ ${ }^{a}$ Department of Cardiology, Faculty of Medicine, Pamukkale University, Denizli, Turkey; ${ }^{\text {b Department of }}$ \\ Hematology, Faculty of Medicine, Pamukkale University, Denizli, Turkey; ${ }^{\mathrm{C}}$ Division of Cardiology, Ardahan State \\ Hospital, Ardahan, Turkey; ${ }^{d}$ Department of Biostatistics, Faculty of Medicine, Pamukkale University, Denizli, Turkey
}

\section{Significance of the Study}

- Pulmonary hypertension can complicate the course of myeloproliferative neoplasm.

- Myelofibrosis is more likely to be associated with pulmonary hypertension.

- Disease duration could predict the development of pulmonary hypertension.

\section{Keywords}

Echocardiography · JAK2V617F mutation · Pulmonary hypertension

\begin{abstract}
Background: Pulmonary hypertension (PH) can complicate the course of myeloproliferative neoplasms (MPNs). Echocardiography is a useful noninvasive screening test for $\mathrm{PH}$ in populations at risk. We aimed to investigate the echocardiographic evidence of $\mathrm{PH}$ and clinical characteristics of patients with MPNs. Methods: This study included 197 patients with MPNs (mean age, $59 \pm 14$ years; females, 53\%; mean disease duration, $3.4 \pm 2.8$ years). Clinical and laboratory characteristics, including JAK2V617F mutation status, were obtained. All participants underwent a comprehensive transthoracic echocardiographic examination. The echocar-
\end{abstract}

\begin{tabular}{ll}
\hline karger@karger.com & $\begin{array}{l}\text { C) } 2020 \text { The Author(s) } \\
\text { Published by S. Karger AG, Basel }\end{array}$ \\
www.karger.com/mpp & This is an Open Access article licensed under the Creative Commons \\
Karger & $\begin{array}{l}\text { Attribution-NonCommercial-4.0 International License (CC BY-NC) } \\
\text { (http://www.karger.com/Services/OpenAccessLicense), applicable to } \\
\text { the online version of the article only. Usage and distribution for com- } \\
\text { mercial purposes requires written permission. }\end{array}$
\end{tabular}

diographic evidence of $\mathrm{PH}$ was defined as systolic pulmonary artery pressure (SPAP) $\geq 40 \mathrm{~mm} \mathrm{Hg}$. Results: Overall, 11 patients (5.5\%) with SPAP $\geq 40 \mathrm{~mm} \mathrm{Hg}$ had echocardiographic evidence of $\mathrm{PH}$. Patients with myelofibrosis had echocardiographic evidence of $\mathrm{PH}$ more often than patients with other MPNs $(p<0.001)$. Disease duration since the diagnosis of MPNs was $6.7 \pm 4.6$ years in the PH group and 3.1 \pm 2.5 years in the non-PH group $(p<0.001)$. There was a weak positive correlation between SPAP values and time since diagnosis ( $r=0.236, p=0.001)$. JAK2V617F mutation was not associated with $\mathrm{PH}$. In multivariate logistic regression analysis, the presence of myelofibrosis (odds ratio [OR]: 22.177, 95\% Cl: 4.480-109.790, $p<0.001)$, long disease duration (OR: $1.217,95 \% \mathrm{Cl}: 1.024-1.447, p=0.026)$, and high uric acid lev-

Y.T. Yaylali and S. Yilmaz contributed equally to this work.

Yalin Tolga Yaylali, MD

Department of Cardiology, Pamukkale University

Camlaraltı Mah. Fakulte Cad. No: 13 Kinikli

TR-20070 Denizli (Turkey)

yaylalimd@gmail.com 
els (OR: $1.868,95 \% \mathrm{Cl}: 1.049-3.328, p=0.034$ ) were found to be related with the echocardiographic evidence of $\mathrm{PH}$. Survival was worse in the $\mathrm{PH}$ group $(p=0.0001)$. Conclusion: Our results suggest that patients with myelofibrosis are more likely to develop PH than other MPNs patients. Disease duration may predict the development of PH in MPN patients.

(c) 2020 The Author(s)

Published by S. Karger AG, Basel

\section{Introduction}

Pulmonary hypertension $(\mathrm{PH})$ is a complex condition that may be related to many clinical conditions [1]. $\mathrm{PH}$ is classified into five groups according to clinical characteristics, pathological findings, hemodynamic characteristics, and treatment response [2]. Group 5 consists of rare diseases that are associated with $\mathrm{PH}$ through multifactorial and/or poorly understood mechanisms [2]. Myeloproliferative neoplasms (MPNs) are included in group 5 $\mathrm{PH}$ [3]. MPNs are characterized by excessive proliferation of one or more blood cells originating from multipotent hematopoietic progenitor cells [4]. Chronic myeloid leukemia, polycythemia rubra vera, essential thrombocytosis, primary myelofibrosis, and hypereosinophilic syndrome are recognized MPNs. Hyperviscosity, platelet activation, and thrombosis occur in polycythemia rubra vera and essential thrombocytosis, which may lead to $\mathrm{PH}$ [4]. In addition, the use of anagrelide, dasatinib, tyrosine kinase inhibitor, or splenectomy in the treatment of MPNs has also been found to be associated with the development of $\mathrm{PH}$ [5-7].

As a result, $\mathrm{PH}$ may develop due to diverse pathophysiological mechanisms in MPNs. The development of PH adversely affects the course of the disease and shortens survival. In this study, we aimed to investigate the relationship between clinical, laboratory characteristics and the echocardiographic evidence of $\mathrm{PH}$ in patients with MPNs.

\section{Patients and Methods}

The study design was retrospective and single centered. A total of 197 patients with the diagnosis of MPNs who presented to hematology and cardiology outpatient clinics participated. All patients had undergone bone marrow aspiration and biopsy. Demographic features, type of MPNs, and disease duration after diagnosis of MPNs were obtained from hospital records. All patients were screened for the presence of JAK2V617F mutation. Patients with a known cause of $\mathrm{PH}$ according to the updated clinical classification, including pulmonary arterial hypertension, $\mathrm{PH}$ due to left heart disease, $\mathrm{PH}$ due to lung diseases and/or hypoxia, $\mathrm{PH}$ due to pulmonary artery obstructions, and $\mathrm{PH}$ with unclear and/or multifactorial mechanisms other than MPNs, were excluded [8].

Transthoracic echocardiography in left lateral decubitus position was performed for each patient. The echocardiographic evidence of PH was based on measurements obtained by transthoracic echocardiography and Doppler study. The evidence of $\mathrm{PH}$ was established if estimated systolic pulmonary artery pressure (SPAP) was $\geq 40 \mathrm{~mm} \mathrm{Hg}$. The estimation of SPAP was calculated by the peak tricuspid regurgitation velocity, taking into account right atrial pressure (RAP) as described by the simplified Bernoulli equation [8]. RAP was estimated by echocardiography based on the diameter and respiratory variation in diameter of the inferior vena cava (IVC): an IVC diameter $<2.1 \mathrm{~cm}$ that collapses $>50 \%$ with a sniff suggested a normal RAP of $3 \mathrm{~mm} \mathrm{Hg}$ (range $0-5 \mathrm{~mm}$ $\mathrm{Hg}$ ), whereas an IVC diameter $\geq 2.1 \mathrm{~cm}$ that collapses $<50 \%$ with a sniff or $20 \%$ on quiet inspiration suggested a high RAP of $15 \mathrm{~mm}$ $\mathrm{Hg}$ (range 10-20 $\mathrm{mm} \mathrm{Hg}$ ). In patients in which the IVC diameter and collapse did not fit this paradigm, an intermediate value of 8 $\mathrm{mm} \mathrm{Hg}$ (range 5-10 $\mathrm{mm} \mathrm{Hg}$ ) was used. In case of the absence of tricuspid regurgitation or the severe presence thereof, additional pre-specified echocardiographic variables that were suggestive of $\mathrm{PH}$ were used as follows: pulmonary artery diameter, ventricular diameter ratio, flattening of the interventricular septum, right ventricle and pulmonary artery hemodynamics, and IVC and right atrium dimensions as recommended by the recent ESC/ERS PH Guidelines [1]. PH is best defined by the presence of mean pulmonary artery pressure $(\mathrm{mPAP})>20 \mathrm{~mm} \mathrm{Hg}$ on right heart catheterization (RHC) [8]. An estimated SPAP of $40 \mathrm{~mm} \mathrm{Hg}$ typically implies an mPAP $>25 \mathrm{~mm} \mathrm{Hg}$ [9]. Confirmation of $\mathrm{PH}$ was obtained by RHC in only 4 patients who gave consent to RHC. All patients with echocardiographic evidence of $\mathrm{PH}$ were seen by a pulmonologist to rule out the presence of chronic obstructive pulmonary disease, obstructive sleep apnea syndrome, and chronic thromboembolic PH. The diagnosis of chronic thromboembolic PH was excluded by normal ventilation/perfusion scans in all participants with echocardiographic evidence of $\mathrm{PH}$.

\section{Statistical Analysis}

The analyses were carried out using SPSS 24 (SPSS Inc., Chicago, IL, USA). To test the distribution pattern, the KolmogorovSmirnov, Shapiro-Wilk method, and skewness and kurtosis results were used. Categorical variables were compared by means of a $\chi^{2}$ test. Yates' correction was used where appropriate. Fisher's exact test was used when expected frequencies were $\leq 5$. Continuous variables were compared by means of the Mann-Whitney U test. Multivariate backward logistic regression analysis was used to detect the independent predictors of PH. Survival analysis was performed using the Kaplan-Meier analysis and log-rank test. A $p$ value $<0.05$ was considered significant.

\section{Results}

Patients were divided into two groups according to SPAP values. Patients who had an SPAP value $\geq 40 \mathrm{~mm}$ Hg comprised the $\mathrm{PH}(+)$ group, whereas patients with an SPAP value $<40 \mathrm{~mm} \mathrm{Hg}$ comprised the $\mathrm{PH}(-)$ group. 
Table 1. Clinical and echocardiographic features of patients

\begin{tabular}{lccc}
\hline & $\begin{array}{l}\text { Pulmonary } \\
\text { hypertension }(+) \\
(n=11)\end{array}$ & $\begin{array}{c}\text { Pulmonary } \\
\text { hypertension }(-) \\
(n=186)\end{array}$ & $p$ \\
\hline Age, years & $64.5 \pm 8.8$ & $59.4 \pm 14.6$ & 0.098 \\
Male sex & $3(25)$ & $88(47.6)$ & 0.129 \\
Disease subgroups & $7(63.6)$ & $16(8.6)$ & $<0.001$ \\
$\quad$ Myelofibrosis & $3(27.2)$ & $80(43.1)$ & \\
$\quad$ Polycythemia vera & $1(9.2)$ & $89(47.8)$ & $<0.001$ \\
$\quad$ Essential thrombocytosis & 0 & $1(0.5)$ & 0.001 \\
$\quad$ Hypereosinophilic syndrome & $6.7 \pm 4.6$ & $3.1 \pm 2.5$ & 0.061 \\
Disease duration, years & $11.1 \pm 2.9$ & $9.9 \pm 2.3$ & 0.172 \\
Hemoglobin, g/dL & $15.5 \pm 26.3$ & $352 \pm 140$ & 0.703 \\
White blood cell count, $\times 10^{9} / \mathrm{L}$ & $287 \pm 271$ & $113 \pm 46$ & 0.005 \\
Platelet count, $\times 10^{9} / \mathrm{L}$ & $119 \pm 30$ & $5.1 \pm 1.2$ & $<0.001$ \\
Glucose, mg/dL & $6.3 \pm 1.9$ & $1.91 \pm 0.57$ & $<0.001$ \\
Uric acid, mg/dL & $3.63 \pm 0.58$ & $18.6 \pm 8.6$ & 0.829 \\
Tricuspid regurgitation velocity, $\mathrm{cm} / \mathrm{s}$ & $58.4 \pm 19.9$ & $59.1 \pm 5.9$ & 0.795 \\
SPAP, mm Hg & $58.5 \pm 4.7$ & $111(59.6)$ & \\
Left ventricular EF & $7(63.6)$ & & \\
Presence of JAK2V617F mutation & & & \\
\hline
\end{tabular}

Data are presented $n(\%)$ or mean \pm standard deviation. SPAP, systolic pulmonary artery pressure; EF, ejection fraction.

Table 2. Multivariate stepwise backward logistic regression analysis results

\begin{tabular}{lrlr}
\hline & Odds ratio & $95 \%$ CI & \multicolumn{1}{l}{$p$} \\
\hline Myelofibrosis & 22.177 & $4.480-109.790$ & $<0.001$ \\
JAK2V617F mutation & 0.551 & $0.105-2.891$ & 0.481 \\
Disease duration & 1.217 & $1.024-1.447$ & 0.026 \\
Hemoglobin & 0.977 & $0.714-1.336$ & 0.883 \\
Uric acid & 1.868 & $1.049-3.328$ & 0.034 \\
\hline
\end{tabular}

CI, confidence interval.

Comparison of basic clinical features, laboratory parameters, and echocardiographic measurements are presented in Table 1. There was no statistically significant difference between the two groups in terms of age and sex. Of the 197 patients, 17 (8.6\%) patients died. The mean SPAP value of patients in the $\mathrm{PH}(+)$ group was $58.4 \pm 19.9 \mathrm{~mm}$ $\mathrm{Hg}$, whereas the mean SPAP value of patients in the $\mathrm{PH}$ $(-)$ group was $18.6 \pm 8.6 \mathrm{~mm} \mathrm{Hg} p<0.001)$. RHC on 5 patients confirmed the presence of $\mathrm{PH} ; 3$ patients had combined pre-and post-capillary $\mathrm{PH}$, whereas 2 patients had pre-capillary PH. JAK2V617F mutation rates were similar between the two groups (63.6 vs. $59.6 \%, p=0.735$ ).
When subgroups of MPNs were analyzed, myelofibrosis was found to be significantly more prevalent in the $\mathrm{PH}$ (+) group (58.3 vs. $8.6 \%, p<0.0001$ ) (Fig. 1). The presence of $\mathrm{PH}$ was greater in myelofibrosis than in polycythemia vera and essential thrombocytosis $(p=0.0001)$. Disease duration since the diagnosis of MPNs was $6.7 \pm 4.6$ years in the $\mathrm{PH}$ group and $3.1 \pm 2.5$ years in the $\mathrm{PH}(-)$ group $(p<0.001)$. In addition, there was a weak positive correlation between SPAP values and time since diagnosis $(r=$ $0.236, p=0.001$ ) (Fig. 2). On multivariate stepwise backward logistic regression analysis, the presence of myelofibrosis (odds ratio [OR]: 22.177, 95\% CI: 4.480-109.790, $p<0.001$ ), disease duration (OR: $1.217,95 \%$ CI: $1.024-$ $1.447, p=0.026$ ), and high uric acid levels (OR: $1.868,95 \%$ CI: $1.049-3.328, p=0.034$ ) were found to be related with $\mathrm{PH}$ (Table 2). Patients with $\mathrm{PH}$ had worse survival than those without $\mathrm{PH}(p=0.0001)$ (Fig. 3).

\section{Discussion}

The main findings of this study were (1) myelofibrosis was the most common subgroup associated with the echocardiographic evidence of $\mathrm{PH},(2)$ disease duration and uric acid levels were associated with the echocardiograph- 
Fig. 1. Distribution of subgroups of myeloproliferative neoplasm based on echocardiographic evidence of pulmonary hypertension.

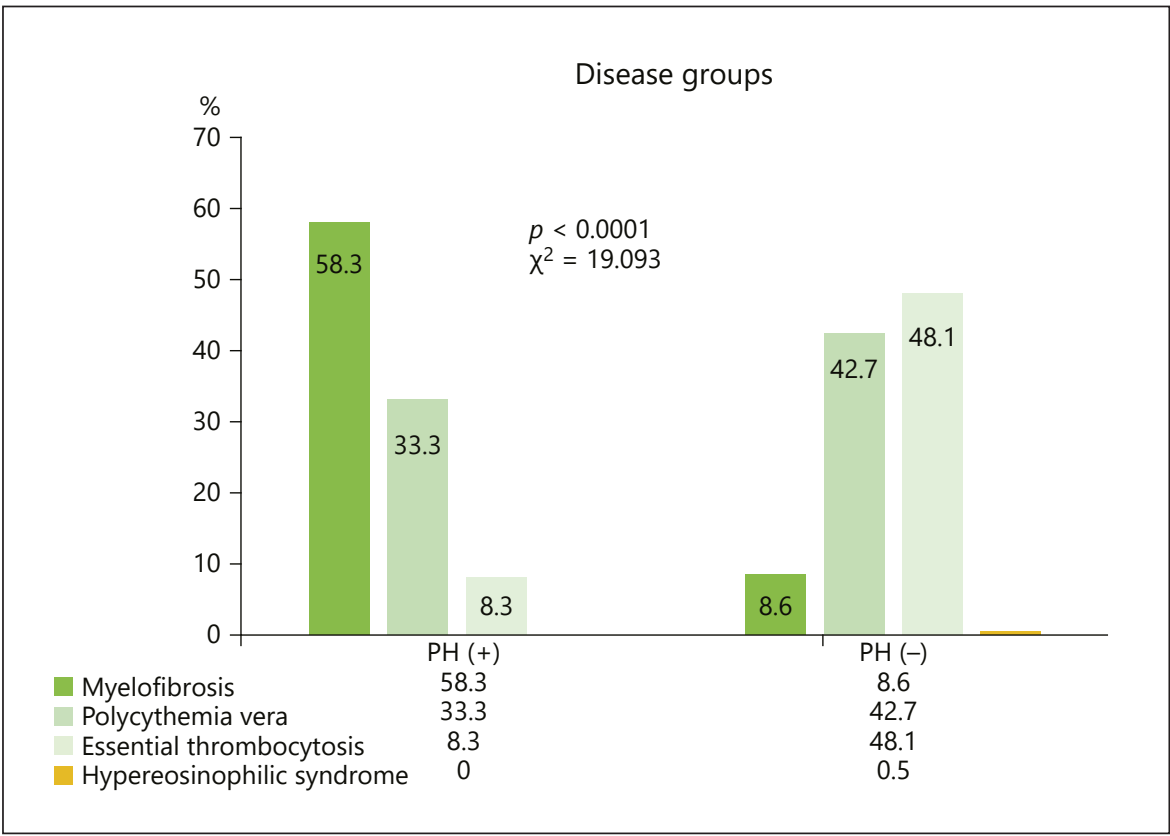

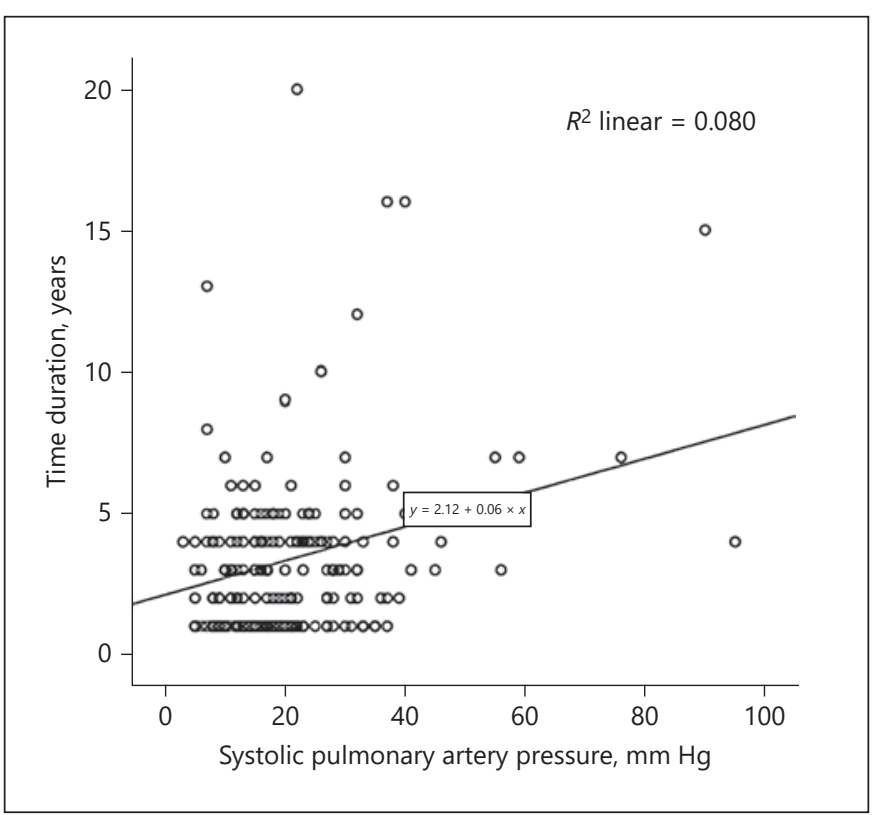

Fig. 2. Correlation between systolic pulmonary artery pressure and time elapsed since diagnosis.

ic evidence of $\mathrm{PH}$, and (3) JAK2V617F mutation was not associated with echocardiographic evidence of $\mathrm{PH}$.

$\mathrm{PH}$ is classified into five groups based on the clinical picture, pathological findings, hemodynamic characteristics, and response to treatment responses [1]. Group 5 consists of rare diseases that are associated with $\mathrm{PH}$

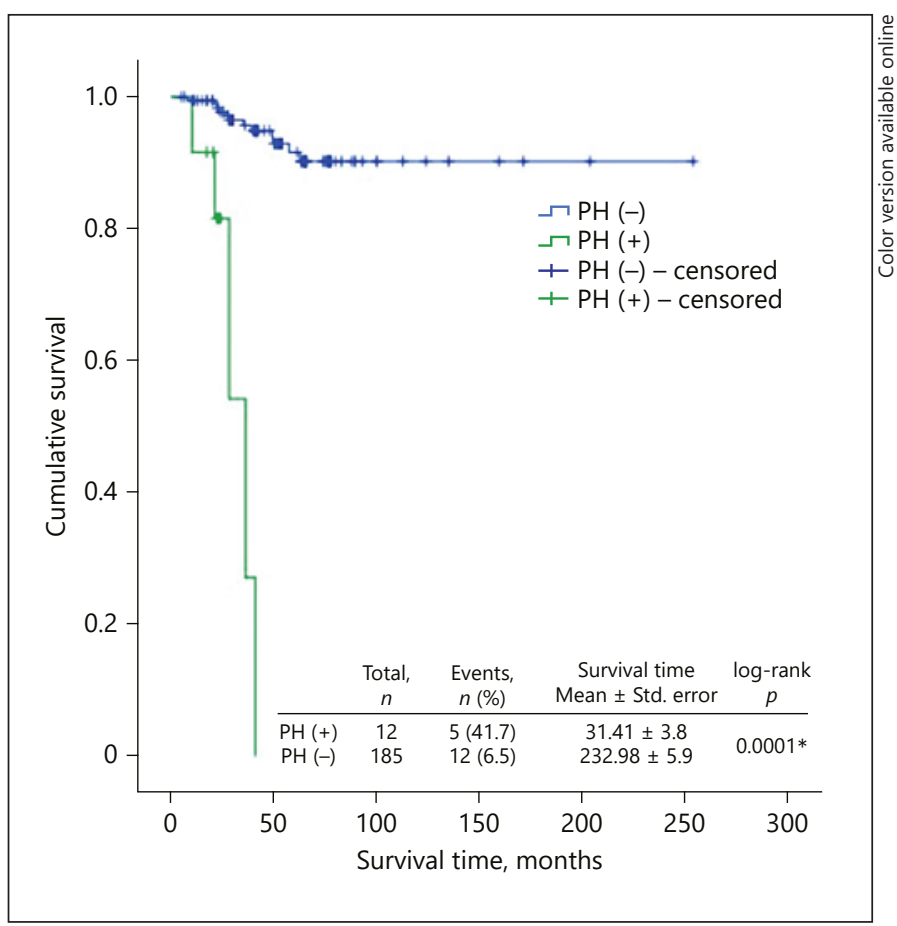

Fig. 3. Survival plot based on the presence of pulmonary hypertension. ${ }^{*} p<0.05$, statistically significant.

through multifactorial and/or poorly understood mechanisms [2]. MPNs are rare causes of $\mathrm{PH}$ which are classified in group 5 [3]. They are characterized by excessive proliferation of one or more blood cells originating from mul- 
tipotent hematopoietic progenitor cells [4]. MPNs cause the development of $\mathrm{PH}$ via multiple mechanisms including pulmonary vasoconstriction of pulmonary arteries and veins, proliferation of pulmonary myocytes, development of fibrosis, parenchymal and vascular destruction, thrombosis, and increased coagulopathy [8]. In addition, there are also cases of $\mathrm{PH}$ related to drugs used in the treatment of MPNs [5, 6]. However, it is not known how and when PH develops in MPNs. In this study, we found a positive correlation between disease duration and echocardiographic evidence of $\mathrm{PH}$.

The prevalence of echocardiographic $\mathrm{PH}$ in MPNs was found to be $5.5 \%$ in our study. Similarly, in another report, the prevalence of $\mathrm{PH}$ was found to be almost $5 \%$ and the mean time since the diagnosis of MPNs was about 15 months [10]. Recently, Venton et al. [11] reported a slightly higher prevalence of $7.7 \%$ with a median follow-up of 46.5 months and the presence of primary myelofibrosis as the main cause. In our study, disease duration was much higher than theirs (6.7 years); however, due to the crosssectional design of our study, it is not possible to confirm the exact time when our patients developed $\mathrm{PH}$.

Myelofibrosis was the most common subgroup in $\mathrm{PH}$ (+) patients in our study. García-Manero et al. [12] investigated the possible mechanisms related to $\mathrm{PH}$ in patients with myelofibrosis. They demonstrated that the development of $\mathrm{PH}$ in patients with myelofibrosis may occur after hematopoietic infiltration of the lung parenchyma, thrombocytosis, thromboembolism, left ventricular failure, and portal hypertension. They also recommended routine Doppler echocardiography to evaluate valvular heart disease and pulmonary artery pressure in all patients with myelofibrosis and dyspnea. In another study investigating the prevalence of unexplained $\mathrm{PH}$ in chronic MPNs, patients with myelofibrosis, polycythemia vera, and essential thrombocytosis had greater prevalence of $\mathrm{PH}[13,14]$. In our study, the prevalence of $\mathrm{PH}$ in patients with polycythemia vera and essential thrombocytosis was not as high. The reason for this may be the relatively lower duration in these patients. There were significantly higher levels of uric acid in patients with $\mathrm{PH}$ in our study. Recently, a large meta-analysis showed a $19 \%$ increased risk of death among patients with $\mathrm{PH}$ who had hyperuricemia, indicating that hyperuricemia may be a prognostic factor for $\mathrm{PH}$ [15]. Survival was worse in the PH group.

Our study did not show a significant relationship between JAK2V617F mutation and the echocardiographic evidence of $\mathrm{PH}$. A similar study investigating the correlation between JAK2V617F allele load and $\mathrm{PH}$ also found no correlation [16].

\section{Limitations}

This was a single-institution and observational study. However, we included all patients who had been followed up with the diagnosis of MPN and who gave informed consent. The evidence of $\mathrm{PH}$ was assessed by echocardiography. We could perform RHC in only 5 patients who had symptoms of heart failure. We could not motivate other patients with echocardiographic evidence of intermediate or high probability for $\mathrm{PH}$ to undergo RHC. The cross-sectional nature of our study did not allow us to find a cause and effect relationship between disease duration and echocardiographic evidence of $\mathrm{PH}$. We could only study JAJ2V617F mutation, because the other mutation profiles were not covered at the time of study. Highresolution computed tomography was performed at the discretion of a pulmonologist. It was not routinely performed to rule out extramedullary hematopoiesis. Survival analyses were limited due to the small sample size.

\section{Conclusions}

The echocardiographic evidence of $\mathrm{PH}$ was found to be related to myelofibrosis, disease duration, and uric acid levels. Patients with myelofibrosis and particularly greater disease duration should be carefully screened for $\mathrm{PH}$ during close follow-up.

\section{Statement of Ethics}

This study was in compliance with the principles outlined in the Declaration of Helsinki. The study protocol was approved by the Medical Ethics Committee (protocolNo.60116787-020/22723). All participants provided informed consent.

\section{Disclosure Statement}

The authors have no conflicts of interest to disclose.

\section{Author Contributions}

Y.T.Y. designed the protocol, reviewed the literature, analyzed the data, and critically reviewed and wrote the manuscript. S.Y. analyzed the data, reviewed the literature, and critically reviewed and wrote the manuscript. G.A.-C. designed the protocol, collected and analyzed the data, and reviewed the literature. O.K. collected and analyzed the data and wrote the manuscript. E.K. collected and analyzed the data. H.S. designed the protocol, analyzed the data, reviewed the literature, and critically reviewed the manuscript. F.O. collected and analyzed the data. 


\section{References}

1 Galiè N, Humbert M, Vachiery JL, Gibbs S, Lang I, Torbicki A, et al.; ESC Scientific Document Group. 2015 ESC/ERS Guidelines for the diagnosis and treatment of pulmonary hypertension: The Joint Task Force for the Diagnosis and Treatment of Pulmonary Hypertension of the European Society of Cardiology (ESC) and the European Respiratory Society (ERS): Endorsed by: Association for European Paediatric and Congenital Cardiology (AEPC), International Society for Heart and Lung Transplantation (ISHLT). Eur Heart J. 2016 Jan;37(1):67-119.

2 Simonneau G, Gatzoulis MA, Adatia I, Celermajer D, Denton C, Ghofrani A, et al. Updated clinical classification of pulmonary hypertension. J Am Coll Cardiol. 2013 Dec; 62(25 Suppl):D34-41.

3 Lahm T, Chakinala MM. World Health Organization group 5 pulmonary hypertension. Clin Chest Med. 2013 Dec;34(4):753-78.

4 Guilpain P, Montani D, Damaj G, Achouh L, Lefrère F, Le Pavec J, et al. Pulmonary hypertension associated with myeloproliferative disorders: a retrospective study of ten cases. Respiration. 2008;76(3):295-302.

5 Willems E, Canivet JL, Ghaye B, de Leval L, Radermecker M, Preiser JC, et al. Pulmonary veno-occlusive disease in myeloproliferative disorder. Eur Respir J. 2009 Jan;33(1):213-6.
6 Montani D, Bergot E, Günther S, Savale L, Bergeron A, Bourdin A, et al. Pulmonary arterial hypertension in patients treated by dasatinib. Circulation. 2012 May; 125(17): 2128-37.

7 Jaïs X, Ioos V, Jardim C, Sitbon O, Parent F, Hamid A, et al. Splenectomy and chronic thromboembolic pulmonary hypertension. Thorax. 2005 Dec;60(12):1031-4.

8 Simonneau G, Montani D, Celermajer DS, Denton CP, Gatzoulis MA, Krowka M, et al. Haemodynamic definitions and updated clinical classification of pulmonary hypertension. Eur Respir J. 2019 Jan;53(1):1801913.

9 Chemla D, Castelain V, Provencher S, Humbert M, Simonneau G, Hervé P. Evaluation of various empirical formulas for estimating mean pulmonary artery pressure by using systolic pulmonary artery pressure in adults. Chest. 2009 Mar;135(3):760-8.

10 Chebrek S, Aïssi K, Francès Y, Mercier C, Farnault $L$, Sébahoun $G$, et al. Pulmonary hypertension in patients with chronic myeloproliferative neoplasms. Leuk Lymphoma. 2014 Jan;55(1):223-5.

11 Venton G, Turcanu M, Colle J, Thuny F, Chebrek S, Farnault L, et al. Pulmonary hypertension in patients with myeloproliferative neoplasms: a large cohort of 183 patients. Eur J Intern Med. 2019 Oct;68:71-5.
12 García-Manero G, Schuster SJ, Patrick H, Martinez J. Pulmonary hypertension in patients with myelofibrosis secondary to myeloproliferative diseases. Am J Hematol. 1999 Feb;60(2):130-5.

13 Gupta R, Perumandla S, Patsiornik Y, Niranjan S, Ohri A. Incidence of pulmonary hypertension in patients with chronic myeloproliferative disorders. J Natl Med Assoc. 2006 Nov;98(11):1779-82.

14 Dingli D, Utz JP, Krowka MJ, Oberg AL, Tefferi A. Unexplained pulmonary hypertension in chronic myeloproliferative disorders. Chest. 2001 Sep;120(3):801-8.

15 Kang TU, Park KY, Kim HJ, Ahn HS, Yim SY, Jun JB. Association of hyperuricemia and pulmonary hypertension: A systematic review and meta-analysis. Mod Rheumatol. 2019 Nov;29(6):1031-41.

16 Mattar MM, Morad MA, El Husseiny NM, Ali $\mathrm{NH}$, El Demerdash DM. Correlation between JAK2 allele burden and pulmonary arterial hypertension and hematological parameters in Philadelphia negative JAK2 positive myeloproliferative neoplasms. An Egyptian experience. Ann Hematol. 2016 Oct;95(10): 1611-6. 